\title{
Polyacidic multiloading metal extractants $\dagger$
}

\author{
Ross J. Gordon, ${ }^{a}$ John Campbell, ${ }^{b}$ David K. Henderson, ${ }^{a}$ Dorothy C. R. Henry, ${ }^{a}$ \\ Ronald M. Swart, ${ }^{b}$ Peter A. Tasker, ${ }^{* a}$ Fraser J. White, ${ }^{a}$ Jenny L. Wood ${ }^{a}$ and \\ Lesley J. Yellowlees ${ }^{a}$
}

Received (in Cambridge, UK) 23rd June 2008, Accepted 9th July 2008

First published as an Advance Article on the web 22nd August 2008

DOI: $10.1039 / \mathrm{b810610j}$

Novel polynucleating, di- and tri-acidic ligands have been designed to increase the molar and mass transport efficiencies for the recovery of base metals by solvent extraction.

Solvent extraction provides highly efficient concentration and separation operations in extractive hydrometallurgy. ${ }^{1}$ Major new plants to recover zinc have opened recently ${ }^{2}$ and $c a .20 \%$ of the global production of copper is achieved using phenolic oxime extractants $^{3}$ (e.g. $\mathbf{L}^{\mathbf{1}} \mathrm{H}$, Fig. 1) in an acid leach-solvent extraction-electrowinning flowsheet (Scheme 1). The latter gives an excellent materials balance for recovery from oxidic ores because the leach, extractant and electrolyte solutions are recycled, and the process can be adapted to work efficiently with wide variation of compositions of pregnant leach solutions. ${ }^{1,4}$

$$
\begin{array}{lll}
\text { Leach } & \mathrm{CuO}_{(\mathrm{s})}+\mathrm{H}_{2} \mathrm{SO}_{4} \rightleftharpoons \mathrm{CuSO}_{4}+\mathrm{H}_{2} \mathrm{O} \\
\text { Extract } & \mathrm{CuSO}_{4}+2 \mathrm{LH} & \rightleftharpoons \mathrm{CuL}_{2}+\mathrm{H}_{2} \mathrm{SO}_{4} \\
\text { Strip } & \mathrm{CuL}_{2}+\mathrm{H}_{2} \mathrm{SO}_{4} \rightleftharpoons \mathrm{CuSO}_{4}+2 \mathrm{LH} \\
\text { Electrowin } \mathrm{CuSO}_{4}+\mathrm{H}_{2} \mathrm{O} \rightleftharpoons \mathrm{Cu}_{(\mathrm{s})}+1 / 2 \mathrm{O}_{2}+\mathrm{H}_{2} \mathrm{SO}_{4} \\
\text { Overall } & \mathrm{CuO}_{(\mathrm{s})} \rightleftharpoons \mathrm{Cu}_{(\mathrm{s})}+1 / 2 \mathrm{O}_{2}
\end{array}
$$

Scheme 1 Materials balance for the recovery of copper from oxidic ores.

Whilst the flowsheet outlined in Scheme 1 is very efficient in terms of the overall materials balance, there is scope to improve the throughput by increasing the transport efficiency in the solvent extraction step. The mass of copper transferred to the water-immiscible solvent in the extraction stage is limited by the $1: 2$ stoichiometry required to generate a neutral, organic soluble, complex from the monoanionic phenolic oxime reagents. We recognized that the molar ratio of copper to extractant could be improved if polynucleating ligands capable of existing as di- or tri-anions after deprotonation were designed. Some systems developed to achieve this are shown in Fig. 1. A key design feature is that the anionic donor atoms, $\mathrm{X}^{-}$or $\mathrm{W}^{-}$in Fig. 1, are able to bridge two $\mathrm{Cu}$ (II) atoms in planar complexes.

\footnotetext{
${ }^{a}$ School of Chemistry, The University of Edinburgh, Edinburgh, UK EH93JJ.E-mail: Peter.Tasker@ed.ac.uk; Fax:+44-131-6506453; Tel: + 44-131-6504706

${ }^{b}$ Cytec Industries Inc, PO Box 42, Blackley, Manchester, UK M9 $8 Z \mathrm{ZS}$

$\dagger$ Electronic supplementary information (ESI) available: Full experimental details. CCDC reference numbers 692604 and 692605. For ESI and crystallographic data in CIF or other electronic format, see DOI: $10.1039 / \mathrm{b} 810610 \mathrm{j}$
}

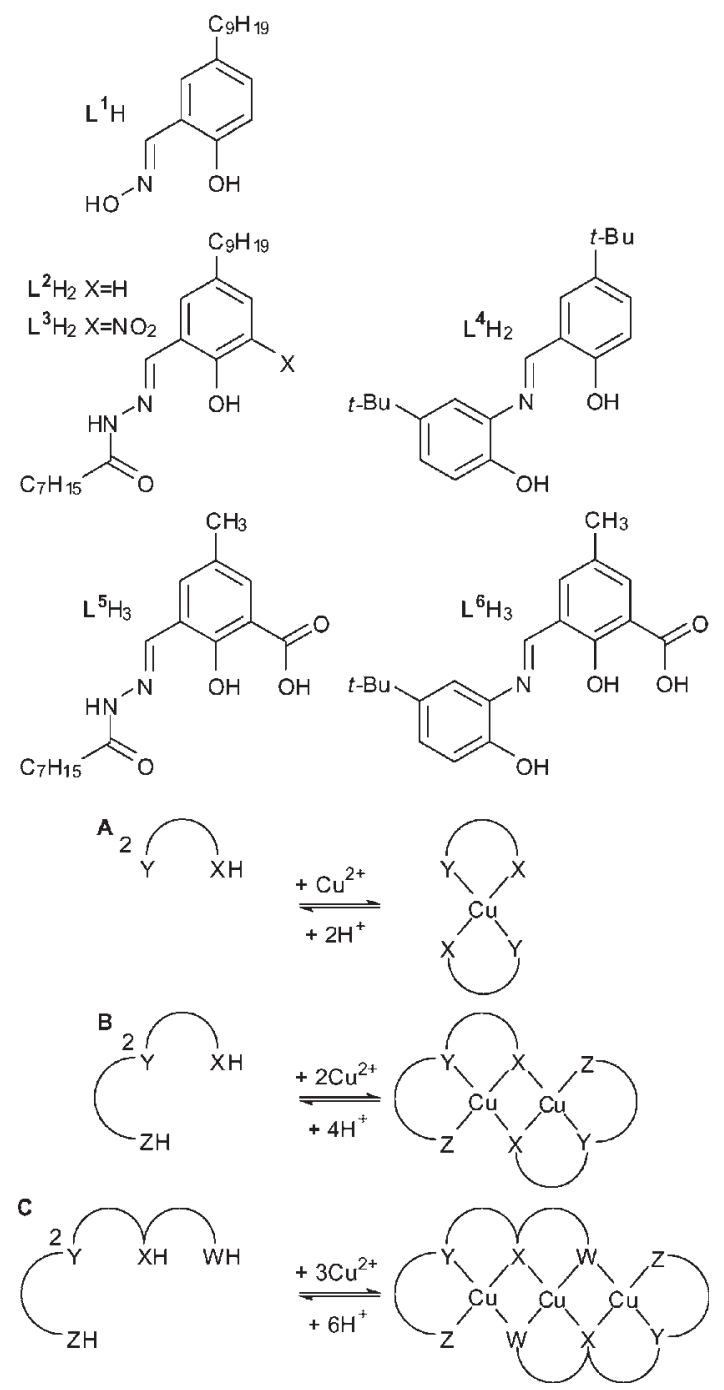

Fig. 1 Functionalization of the conventional type of extractant $\mathbf{L}^{\mathbf{1}} \mathbf{H}$ to generate di- and tri-acidic reagents $\mathbf{L}^{2} \mathrm{H}_{2}-\mathbf{L}^{6} \mathrm{H}_{3}$ which can form di- and tri-nuclear $\mathrm{Cu}(\mathrm{II})$ complexes (B and $\mathbf{C})$.

Studies of the $\mathrm{pH}$-dependence of $\mathrm{Cu}(\mathrm{II})$ extraction into chloroform solutions using the ligands (Fig. 2) show that the metal to ligand stoichiometry can be increased from $1: 2$ to $2: 2$ or $3: 2$, corresponding to 100,200 and $300 \% \mathrm{Cu}$-loading for ligands $\mathbf{L}^{1} \mathbf{H}, \mathbf{L}^{2} \mathrm{H}_{2}$ to $\mathbf{L}^{4} \mathrm{H}_{2}$ or $\mathbf{L}^{5} \mathrm{H}_{3}$, respectively. The loading curves (Fig. 2) for $\mathbf{L}^{3} \mathrm{H}_{2}$ and $\mathbf{L}^{5} \mathrm{H}_{3}$ show plateaux which indicate that stepwise loading is possible, e.g. in 


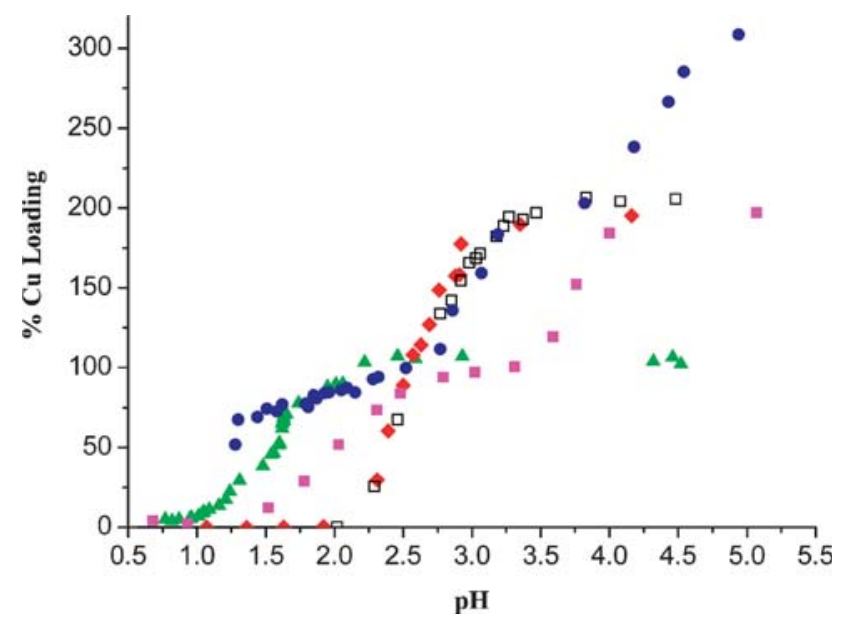

Fig. 2 Cu-loading by $\mathrm{CHCl}_{3}$ solutions of $\mathbf{L}^{1} \mathrm{H}(\boldsymbol{\Delta}), \mathbf{L}^{2} \mathrm{H}_{2}(\diamond), \mathbf{L}^{3} \mathrm{H}_{2}$ ( $\mathbf{n}), \mathbf{L}^{4} \mathrm{H}_{2}(\square)$ and $\mathbf{L}^{5} \mathrm{H}_{3}(\bullet)$ as a function of $\mathrm{pH}$. Loadings of 100 , 200 and $300 \%$ correspond to $\mathrm{Cu}: 2 \mathrm{~L}, 2 \mathrm{Cu}: 2 \mathrm{~L}$ and $3 \mathrm{Cu}: 2 \mathrm{~L}$ molar ratios.

addition to forming species with a stoichiometry consistent with the desired trinuclear complex, $\left[\mathrm{Cu}_{3}\left(\mathbf{L}^{5}\right)_{2}\right]$, at $\mathrm{pH}>5$ the ligand $\mathbf{L}^{5} \mathrm{H}_{3}$ also forms species corresponding to mono- or dinuclear complexes, $\left[\mathrm{Cu}\left(\mathbf{L}^{5} \mathrm{H}_{2}\right)_{2}\right]$ and $\left[\mathrm{Cu}_{2}\left(\mathbf{L}^{5} \mathrm{H}\right)_{2}\right]$, at $\mathrm{pH}$ values of $c a .2 .2$ or 3.8 , respectively.

The Cu-uptake by chloroform solutions of $\mathbf{L}^{2-4} \mathrm{H}_{2}$ can be followed by monitoring X-band EPR spectra. The intensity of the signal increases (A in Fig. 3) until the $\mathrm{Cu}$-loading corresponds to a metal to ligand stoichiometry of $1: 2$. Further loading is accompanied by a decrease in signal intensity (B in
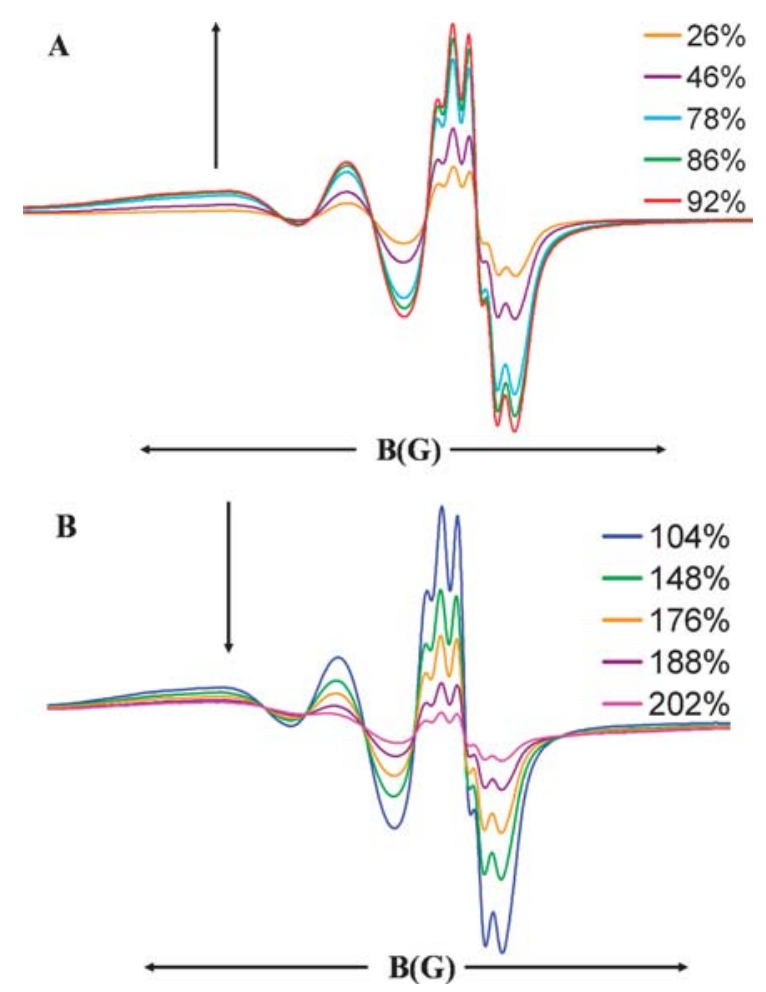

Fig. 3 EPR spectra of $\mathrm{CHCl}_{3}$ solutions of $\mathbf{L}^{2} \mathrm{H}_{2}$ as $\mathbf{C u}$-loading increases from $0-100 \%$ (curves A) and from 100-200\% (curves B).

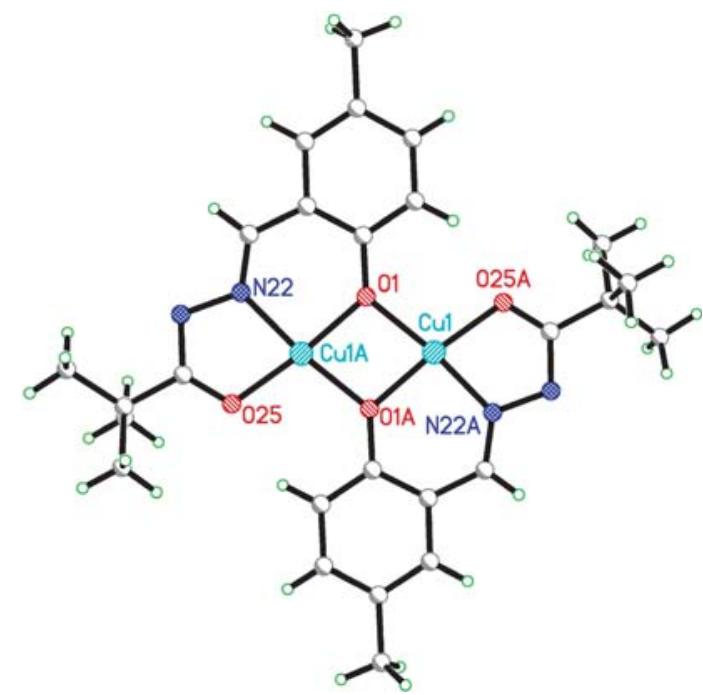

Fig. 4 Dinuclear copper complex of a structural analogue of $\mathbf{L}^{2} \mathbf{H}_{2}$.

Fig. 3) and at 2:2 stoichiometry there is almost no signal. Antiferromagnetic coupling between the two copper centres in the dinuclear complexes could account for these changes. There is some ambiguity as to the structure of the dinuclear complexes, and in particular which of the oxygen atoms in $\mathbf{L}^{2-4} \mathrm{H}_{2}$ or $\mathbf{L}^{5-6} \mathrm{H}_{3}$ form bridges between the two $\mathrm{Cu}$ atoms. An analogue of $\mathbf{L}^{2} \mathrm{H}_{2}$, with $t$-Bu and $\mathrm{Me}$ groups replacing the heptyl and nonyl substituents, gives a complex (Fig. 4) $\ddagger$ which is similar to several reported in the $\mathrm{CSD}^{5}$ in which the phenolate oxygen atom of the salicylaldimine component bridges the two copper centres. In contrast, in the dinuclear complex (Fig. 5) $\ddagger$ formed by $\mathbf{L}^{6} \mathrm{H}_{3}$, it is another type of phenolate oxygen atom which forms the bridges and much more irregular $\mathrm{NO}_{3}{ }^{2-}$ donor sets are presented to the copper atoms by the ligands.

Whilst the new di- and tri-acidic extractants increase the molar transport efficiency two or three fold, it is the mass transport which is of greater practical significance. Based on the molecular weights shown in Table 1 , it can be seen that

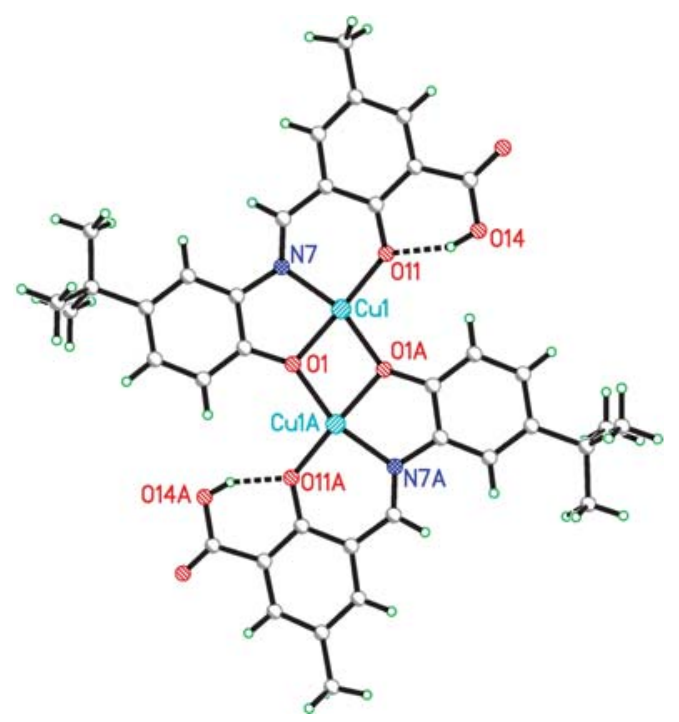

Fig. 5 Crystal structure of dinuclear copper complex of $\mathbf{L}^{6} \mathrm{H}_{3}$. 
Table 1 Comparison of the mass transport efficiencies $\mathbf{L}^{2-4} \mathrm{H}_{2}$, and $\mathbf{L}^{5} \mathrm{H}_{3}$ with the commercial extractant, 5-nonylsalicylaldoxime $\left(\mathbf{L}^{1} \mathbf{H}\right)$

\begin{tabular}{|c|c|c|c|c|}
\hline \multirow[b]{2}{*}{ Reagent } & \multirow[b]{2}{*}{$M_{\mathrm{r}}$} & \multirow[b]{2}{*}{$\begin{array}{l}\text { Stoichiometry } \\
(\mathrm{Cu}: \mathrm{L})\end{array}$} & \multicolumn{2}{|c|}{$\mathrm{Cu}$ Transport } \\
\hline & & & $\begin{array}{l}\mathrm{g} \text { per } \mathrm{kg} \\
\text { reagent }\end{array}$ & $\begin{array}{l}\text { Relative } \\
\text { to } \mathbf{L}^{\mathbf{1}} \mathbf{H}\end{array}$ \\
\hline$\overline{\mathbf{L}^{1} \mathrm{H}}$ & 263 & $1: 2$ & 121 & 1.00 \\
\hline $\mathbf{L}^{2} \mathrm{H}_{2}$ & 388 & $2: 2$ & 164 & 1.36 \\
\hline $\mathbf{L}^{3} \mathrm{H}_{2}$ & 433 & $2: 2$ & 147 & 1.21 \\
\hline $\mathbf{L}^{4} \mathrm{H}_{2}$ & 325 & $2: 2$ & 195 & 1.62 \\
\hline $\mathbf{L}^{5} \mathrm{H}_{3}$ & 320 & $3: 2$ & 298 & 2.47 \\
\hline
\end{tabular}

between 1.36 to 2.47 fold improvements relative to the commercial extractant 5-nonylsalicylaldoxime $\left(\mathbf{L}^{1} \mathrm{H}\right)$ result from using the reagents $\mathbf{L}^{\mathbf{2}} \mathrm{H}_{2}$ to $\mathbf{L}^{5} \mathrm{H}_{3}$.

Exploiting the improved transport efficiency of these new reagents will only be possible if they have high solubility in the hydrocarbon solvents used industrially and are stable to hydrolysis and show selectivity for $\mathrm{Cu}$-loading in the low $\mathrm{pH}$ ranges used in commercial circuits. Nevertheless, the work described in this communication has shown that substantial increases in mass transport efficiency are possible by designing multi-loading extractants which incorporate into the ligand super structure several acidic groups which can function in a metal-metal bridging mode.

The authors thank Cytec Industries Inc. and EPSRC for funding.

\section{Notes and references}

$\ddagger$ Crystal data for $\left[\mathrm{Cu}_{2} \mathrm{~L}_{2}\right] \cdot 2 \mathrm{CHCl}_{3}$ (Fig. 4):

Data were collected on a 3 circle Bruker Smart Apex CCD diffractometer with graphite-monochromated Mo-K $\alpha$ radiation $(\lambda=$ $0.71073 \AA$ ) equipped with an Oxford Cryosystems low temperature device operating at $150 \mathrm{~K}$. The crystal was indexed using the Bruker Smart software ${ }^{6}$ and found to be triclinic with $a=5.9794(3), b=$ 9.9352(5), $c=15.3792(9) \AA$, and $\alpha=98.853(4), \beta=94.933(4), \gamma=$ $103.343(4)^{\circ}$. From initial indexing a data collection strategy was refined which aimed to collect fully complete data to a resolution of $53^{\circ}$ in $2 \theta$ in as short a time as possible. In total 8149 reflections were collected and from these the space group was determined to be $P \overline{1}$. Absorption correction was performed using a multi-scan method by applying the $\mathrm{SADABS}^{7}$ program to the data. The data were merged according to the crystal system in $\mathrm{SHELX}^{8}$ which gave 3052 unique reflections with a merging $R$-factor of 0.0442 . The initial solution was determined by direct methods with the SHELXS ${ }^{8}$ program. All heavy atoms were refined anisotropically and hydrogen atoms were placed geometrically and allowed to ride on their host atom. Full matrix least squares refinement was carried out against $F^{2}$ producing a final conventional $R$-factor of 0.0957 based on 2750 reflections.
Crystal data for $\left[\mathrm{Cu}_{2}\left(\mathbf{L}^{6} \mathrm{H}\right)_{2}\right]$ (Fig. 5):

Data were collected on a 3 circle Bruker Smart Apex CCD diffractometer with graphite-monochromated Mo-K $\alpha$ radiation $(\lambda=$ $0.71073 \AA$ ) and equipped with an Oxford Cryosystems low temperature device operating at $150 \mathrm{~K}$. The crystal was indexed using the Cell_now indexing program ${ }^{9}$ and found to be triclinic with $a=$ 6.8829(7), $b=9.6493(10), c=12.3771(12) \AA$ and $\alpha=88.498(6)$, $\beta=83.850(6), \gamma=83.339(6)^{\circ}$. The crystal was also twinned and the twin law obtained after global cell refinement was $(-0.99434-0.00064$ $-0.02085), \quad(0.00755-0.99936-0.01644), \quad\left(\begin{array}{llll}-0.43677 & -0.05385\end{array}\right.$ 0.99478). From initial indexing a data collection strategy was refined which aimed to collect fully complete data to a resolution of $53^{\circ}$ in $2 \theta$ in as short a time as possible. In total 3802 reflections were collected and from these the space group was determined to be $P \overline{1}$. Absorption correction was performed using a multi-scan method by applying the TWINABS ${ }^{10}$ program to the data. The initial solution was determined by direct methods with the SHELXS ${ }^{8}$ program. All heavy atoms were refined anisotropically and hydrogen atoms were placed geometrically and allowed to ride on their host atom. Full matrix least squares refinement was carried out against $F^{2}$ producing a final conventional $R$-factor of 0.0865 based on 3091 reflections.

1 P. A. Tasker, P. G. Plieger and L. C. West, in Comprehensive Coordination Chemistry II, ed. J. A. McCleverty and T. J. Meyer, Elsevier, Oxford, UK, 2004, vol. 9, p. 759.

2 G. Borg, K. Karner, M. Buxton, R. Armstrong and S. W. Van Der Merwe, Econ. Geol., 2003, 98, 749.

3 P. J. Mackey, CIM Mag., 2007, 2, 35-42.

4 J. Szymanowski, Hydroxyoximes and Copper Hydrometallurgy, CRC Press, London, 1993.

5 (a) E. W. Ainscough, A. M. Brodie, A. J. Dobbs, J. D. Ranford and J. M. Waters, Inorg. Chim. Acta, 1998, 267, 27; (b) S. C. Chan, L. L. Koh, P. H. Leung, J. D. Ranford and K. Y. Sim, Inorg. Chim. Acta, 1995, 236, 101; (c) P. M. Haba, O. Diouf, A. Sy, M. L. Gaye, A. S. Sall, A. H. Barry and T. Jouini, Z. Kristallogr. - New Cryst. Struct., 2005, 220, 479; (d) M. F. Iskander, L. El-Sayed, N. M. H. Salem, W. Haase, H. J. Linder and S. Foro, Polyhedron, 2004, 23, 23; (e) V. A. Kogan, V. V. Lukov, S. I. Levchenkov, M. Y. Antipin and O. V. Shishkin, Mendeleev Commun., 1998, 145; $(f)$ W. G. Lu, C. H. Peng, H. W. Liu and X. L. Feng, Chin. J. Inorg. Chem., 2003, 19, 1222; (g) A. Roth, A. Buchholz, M. Gartner, A. Malassa, H. Gorls, G. Vaughan and W. Plass, Z. Anorg. Allg. Chem., 2007, 633, 2009; (h) N. R. Sangeetha, K. Baradi, R. Gupta, C. K. Pal, V. Manivannan and S. Pal, Polyhedron, 1999, 18, 1425; (i) V. F. Shulgin, O. V. Konnik, K. V. Rabotyagov, V. M. Novotortsev, O. G. Ellert, V. M. Shcherbakov, I. L. Eremenko, S. E. Nefedov and Y. T. Struchkov, Zh. Neorg. Khim., 1994, 39, 1486; (j) P. E. Werner, A. Valent, V. Adelskold and O. Svajlenova, Acta Chem. Scand., Ser. A, 1983, 37, 51.

6 Smart software, Bruker-Nonius, Bruker-AXS, Madison, Wisconsin, USA, 2002.

7 G. M. Sheldrick, SADABS, Program for area detector adsorption correction, Bruker-AXS, Madison, Wisconsin, USA, 2004.

8 G. M. Sheldrick, Acta Crystallogr., Sect. A: Found. Crystallogr., 2008, 64, 112.

9 G. M. Sheldrick, Cell_now indexing program, Bruker-AXS, Madison, Wisconsin, USĀ, 2004.

10 G. M. Sheldrick, TWINABS software, University of Gottingen, Germany, 2003. 